Research Article

Hameed Sa’ad, Bamidele D. Omoleyomi, Elijah A. Alhassan*, Ezekiel O. Ariyo, and Taiwo Abadunmi

\title{
Mechanical performance of abrasive sandpaper made with palm kernel shells and coconut shells
}

https://doi.org/10.1515/jmbm-2021-0004

Received Oct 07, 2020; accepted Mar 01, 2021

Abstract: The use of agricultural wastes as additives for other valuable products has been the focus of many research efforts because of their availability, inherent properties, and environmental friendliness. Palm kernel shells (PKS) and coconut shells (CNS) are agricultural solid end products obtainable from the cracking of their fruit nuts. In this study, PKS and CNS were used to produce abrasive sandpaper following established procedures. The mechanical properties of the sandpaper produced were established. Material for application in abrasive operations must exhibit maximum hardness and compressive strength, minimal wear rate, water absorption, and density. Results showed a $20 \%$ and $25 \%$ increment in specimen hardness values for PKS and CNS respectively in samples with polyester resin content weight composition range of $7.8-22.2 \%$ based on sieve size of $250 \mu \mathrm{m}$. Similarly, 29.23\% and 32.44\% increment for PKS and CNS respectively was recorded for a sieve size of $420 \mu \mathrm{m}$. Samples with a high percentage of binder exhibit better wear characteristics for both PKS and CNS for the investigated parameters. As the percentage weight composition of PKS and CNS samples increases in the abrasive sandpaper composites, the water absorption properties decrease for both $250 \mu \mathrm{m}$ and $420 \mu \mathrm{m}$ sieve sizes. Samples compressive strength increases as the percentage weight composition of binder increases over a range of 7.8 to $22.2 \%$ for both $250 \mu \mathrm{m}$ and $420 \mu \mathrm{m}$ sieve sizes studied. Similarly, as the percentage weight composition of PSK and CNS increases, the sample exhibit high density for both sieve sizes. These characteristics affirmed the suitability of the abrasive composites made with PKS and CNS for frictional applications.

Keywords: agricultural wastes, palm kernel shell (PKS), coconut shell (CNS), abrasive sandpaper, tribology

\footnotetext{
*Corresponding Author: Elijah A. Alhassan: Department of Agricultural and Biosystems Engineering, Landmark University, Omu Aran, Nigeria; Email: alhassan.elijah@lmu.edu.ng
}

๖ Open Access. (๖ 2021 H. Sa'ad et al., published by De Gruyter (cc) BY License

\section{Introduction}

An increase in population coupled with a corresponding increase in demand for agricultural products has resulted in enormous generations of agricultural wastes that pose a challenge to farmers in terms of their proper handling, management, and disposal. Most often in Nigeria's farming perspective, these wastes have near-zero commercial or economic usage hence constituting a menace to the environment [1]. Their alternative utilization as raw materials for other valuable products has recently gained attention among researchers. Hence, an increased interest in the effective and efficient ways of appropriating agricultural wastes as an alternative source of raw materials [2, 3]. Agricultural wastes are made up of organic compounds from living or dead plants like rice husk and straw, oil palm shell, coconut shell, sugarcane bagasse, maize cob and husk, groundnut shell, etc. The huge volume of these generated annually is to a very great extent not adequately used in Nigeria [1, 4]. The proper utilization of these wastes for other essential products will be of economic benefit to the farmers as they can serve as an additional source of income, and also will help in the protection of the environment $[5,6]$. The need to convert these agricultural wastes into industrial consumables such as sandpaper is worth undertaking because of the significance of abrasive machining to the manufacturing sector economy.

Palm oil and coconut plants belong to the same palm family with almost the same taxonomic hierarchy. They are domestic plants that are well suited to Nigeria's ecoclimatic conditions. Products from these plants are in high demand because of inherent distinctive nutrients and wide industrial applicabilities for varied domestics products. The global palm oil production outlook shows Nigeria as the fifth-largest producer. A major challenge associated with palm fruits and coconuts processing is the huge volume

Hameed Sa'ad, Bamidele D. Omoleyomi, Ezekiel O. Ariyo, Taiwo Abadunmi: Department of Agricultural and Biosystems Engineering, University of Ilorin, Ilorin, Nigeria 
of biomass produced in the process [7]. These are palm bunches, palm fibre, and palm kernel, and coconut shell [8]. Some of these byproducts have been used in combination with other raw materials for the production of useful products like particleboard, concrete, car brake pads, sandpaper, briquette, biofuel, that have found applications in building and highway construction, automotive industry, as electrical insulators, lagging and packaging materials, and feedstock for power generations [6, 9-14].

Sandpapers are papers with friction or abrasive material bound to the surface. They consist of abrasive particles of a single layer attached to a flexible backing material by a bonding agent [5]. They are primarily used for sanding and smoothing in wood, metal, sculptural, and architectural works. An abrasive is used to form or finish a workpiece through rubbing which leads to part of the workpiece being worn off by friction. Processing of abrasive materials involved furnace treatment, pulverization, and sifting into different grain sizes known as grits [15]. They possess important physical properties such as hardness, toughness, brittleness, failure characteristics, purity, shape, size, and the uniformity of the grains. Abrasive materials could be obtained naturally or synthetically produced. Natural abrasive materials such as alumni silicate mineral, chalk, lime, diatomite, diamond, silica, and kaolinite can be used to manufacture abrasive grains [16]. The synthetics are those that are usually produced with controlled quantities and compositions. The synthetic abrasive materials have purity as an important feature that has significant relevance to their efficiency [17]. The most pronounced synthetic abrasive materials based on usage are aluminum oxide, silicon carbide, and Cubic Boron Nitride (CBN). Aluminum oxide and silicon carbide are the most prominent materials being utilized recently. Some researchers have developed abrasive sandpapers using locally sourced materials. Obot et al. [18] carried out a comparative analysis of abrasive sandpaper produced from the periwinkle shell and palm kernel shell. Wai and Lilly [19] also researched the production of emery cloth/sandpaper from locally sourced materials while Odior and Oyawale [20] investigated the preparation and production of silicon carbide abrasives with materials that were locally sourced. These affirmed the potential inherent in agricultural waste materials in the manufacturing of abrasive sandpapers for domestic and commercial uses.

Using palm kernel and coconut shells as abrasive materials would be an eco-friendly solution to the waste management challenges of these palms biomass. As different materials exhibit different behaviour because of their grain mass compositions, establishing their mechanical properties is a requisite approach for their application and performance. Hence, this study developed abrasive sandpaper using palm kernel and coconut shells. The formed samples were subjected to mechanical tests to establish their hardness, wear rate (WR), water absorption (WA), compressive strength (CS), and density (D).

\section{Materials and methods}

\subsection{Experimental materials and equipment used}

The experimental materials are palm kernel shell (PSK), coconut shell (CNS), polyester resin (binder), Methyl Ethyl Ketone Peroxide, MEKP (hardener), cobalt naphthalene (accelerator), water, SAE 60 automotive engine oil, and containers.

Similarly, major equipment and tools for samples formation and mechanical behaviour analyses are Universal Testing Machine (INSTRON, Model 3369, USA), Rockwell micro hardness machine (LECO, LM700AT, USA), Taber abrasion tester (TST, Model TSE-A016, China), pin on disk machine (Sushant Engineers, Model GST-120, India), ball milling machine, mechanical mixer, vibrating sieving machine, aluminum moulds, electronic weighing balance (CAC, Model CAC-25, India), scrapper, hand gloves, metal files, steel spatula, and stirrer.

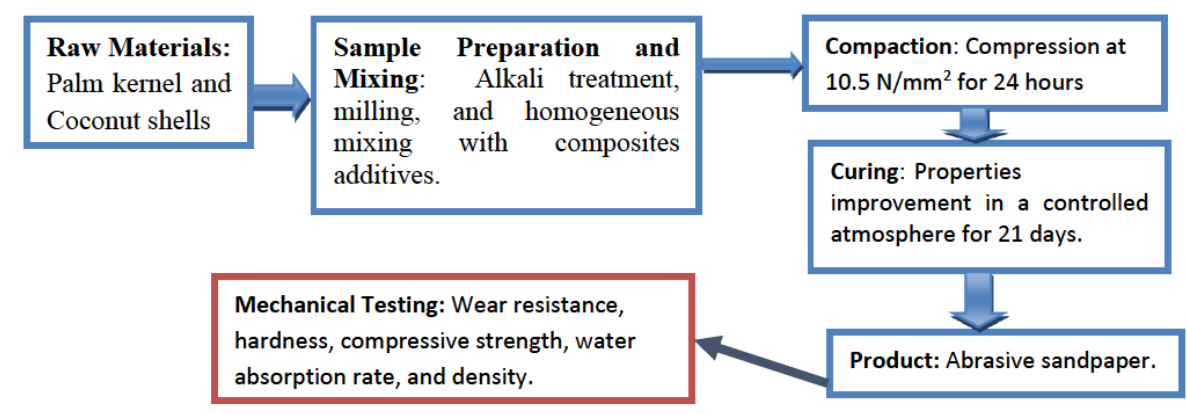

Figure 1: Procedural steps followed for abrasive sandpaper production 


\subsection{Research conceptual framework}

The steps for the production of abrasive sandpaper from PKS and CNS are as depicted in Figure 1. This relates the raw materials for composites formation to the inherent mechanical properties exhibited by them following standard procedures for sample production and analysis.

\subsection{Preparation of material samples and abrasive sandpaper specimen production}

Experimental specimens were painstakingly prepared following established procedures to remove contaminants that may impede the solid formation of abrasive sandpaper [21-24]. Raw materials for sample preparation were sourced from a farm at Igbo Owu and Oja Oba market in Kwara State. They were suspended in a solution of caustic soda $(\mathrm{NaOH})$ for 24 hours to remove the oil remnant left after oil processing procedures [9]. This was followed by thorough washing with clean water and sun-drying for 5 days of the experimental specimens. Oven drying of the sample was also done at $100^{\circ} \mathrm{C}$ for 5 hours until a constant moisture level was attained. Samples were fed into a ball milling machine to form the needed powder which was sieved using $250 \mu \mathrm{m}$ and $420 \mu \mathrm{m}$ sieve sizes (ASTM E11) to sort the grain sizes into FEPA abrasive grits of P60 and P40 standard grits respectively [25].

Other constituent elements of the abrasive composites were graded and stored properly in well-labeled transparent glass containers for easy identification. The production of the abrasive specimen followed the technique of powder metallurgy as used by [18]. The sample mass composition is presented in Table 1 and Figure 2 shows the specimen grits based on $250 \mu \mathrm{m}$ and $420 \mu \mathrm{m}$ sieve sizes.

The required quantity of milled PKS and CNS samples were measured using a digital weighing balance which was discharged into a clean separate plastic container. The measure of the right proportion of binder, accelerator, and hardener was added in succession to the PKS and CNS samples in their separate containers. Thorough mixing was done for
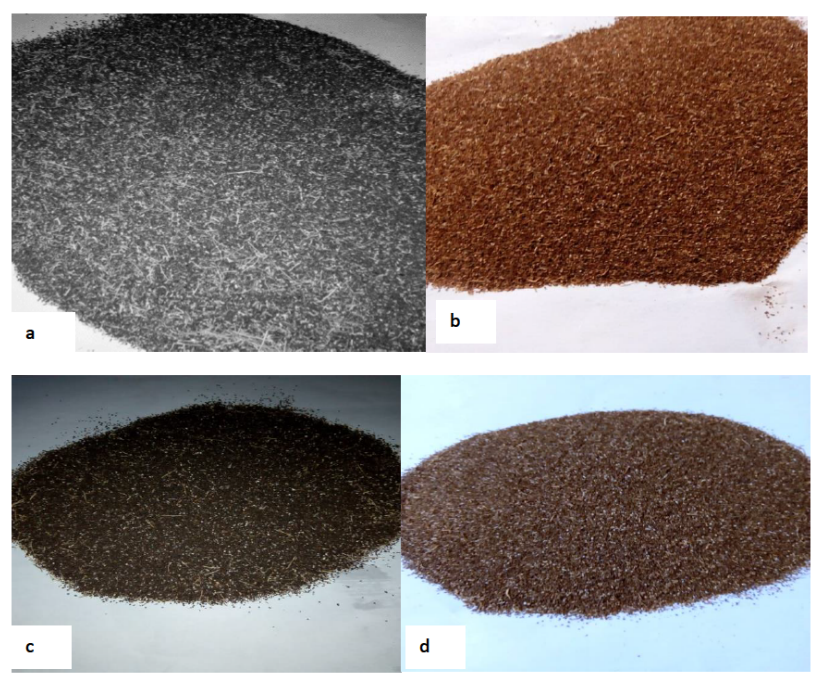

Figure 2: (a) $250 \mu \mathrm{m}$ PKS sample, (b) $250 \mu \mathrm{m}$ CNS sample, (c) $420 \mu \mathrm{m}$ PKS sample, (d) $420 \mu \mathrm{m}$ CNS sample

15 minutes to achieve homogeneity of the prepared specimens. The paste-like uniform mixture obtained was fed into the mould cavities powdered talc for easy component removal after casting. A fixed pressure of $10.5 \mathrm{~N} / \mathrm{mm}^{2}$ at room temperature was used to compact the specimen. The samples were left under compression for 24 hours after which they were gently removed and left to cool for 80 to 120 minutes. Specimens having high binder content tend to exhibit resistance to the flow of paste and composites elements also influence the curing duration. The specimens produced were stored in a well-ventilated room for 21 days for full strength attainment before performing the mechanical tests to ascertain the suitability of the formulation for frictional applications [26].

\subsection{Compression mould development}

The developed mould of dimensions $65 \mathrm{~mm}$ diameter by 45 $\mathrm{mm}$ depth for the production of the abrasive sandpaper was operated manually with a constant pressure of $10.5 \mathrm{~N} / \mathrm{mm}^{2}$. Figure 3 shows the schematic and design drawings of the

Table 1: Mass composition of the abrasive sandpaper composites

\begin{tabular}{ccccc}
\hline PKS $/$ CNS $(\mathrm{g})$ & Resin $(\mathrm{g})$ & Hardener $(\mathrm{g})$ & Accelerator $(\mathrm{g})$ & Total Mass $(\mathrm{g})$ \\
\hline 50.4 & 14.8 & 0.8 & 0.8 & 66.8 \\
52.8 & 12.4 & 0.8 & 0.8 & 66.8 \\
55.2 & 10.0 & 0.8 & 0.8 & 66.8 \\
57.6 & 7.6 & 0.8 & 0.8 & 66.8 \\
60.0 & 5.2 & 0.8 & 0.8 & 66.8 \\
\hline
\end{tabular}



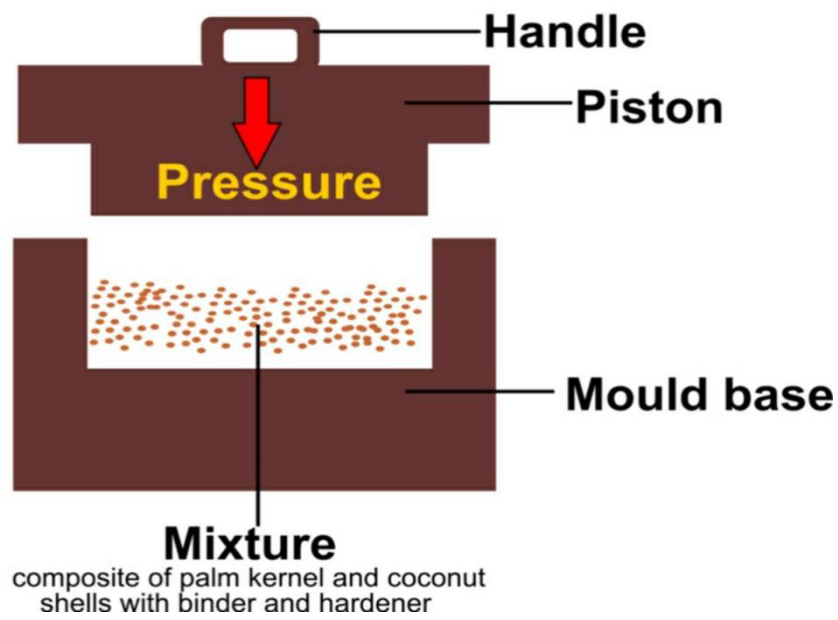

a

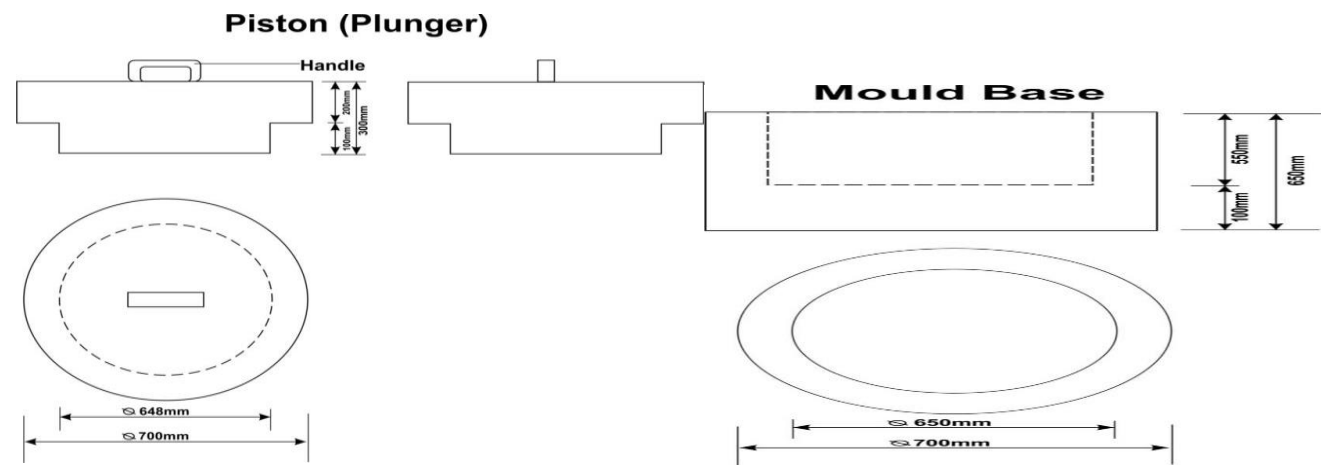

b

Figure 3: (a) Schematic components of the compression mould (b) Design drawings of piston and mould base, dimensions in mm

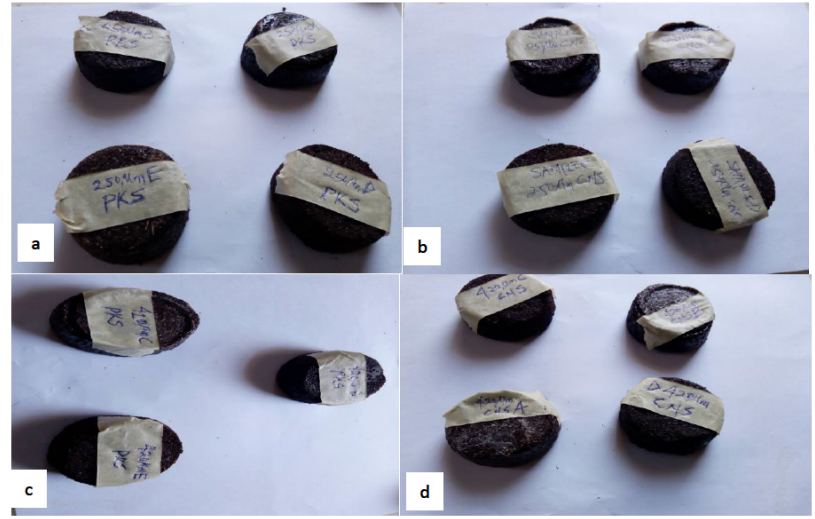

Figure 4: Composites abrasive sandpaper matrix from (a) PKS of $250 \mu \mathrm{m}$ sieve size (b) CNS of $250 \mu \mathrm{m}$ sieve size (c) PKS of $420 \mu \mathrm{m}$ sieve size (d) CNS of $420 \mu \mathrm{m}$ sieve size

compression mould while Figure 4 depicts the abrasive sandpaper formed from the additive composites.

\subsection{Mechanical properties test techniques}

Standard tests were used to determine the empirical values of the vital abrasive analytical parameters.

\subsubsection{Hardness test method}

The PKS and CNS composites hardness characteristics were established following procedures in the American Society of Testing and Materials (ASTM V03.01-2020). The Rockwell hardness tester on "B" scale (38506) with a $1.56 \mathrm{~mm}$ steel ball indenter minor load of $10 \mathrm{~kg}$, a major load of $100 \mathrm{~kg}$, and a standard block of hardness value of 101.2HRB was used. Hardness affirmed resistance to indentation, determined by measuring the indentation permanent depth. The Rockwell method measures the permanent depth of indentation produced by a force/load on an indenter. The steps involve a preliminary test force also known as the preload or minor load, $\mathrm{F}_{0}$ is applied to a sample using a diamond or ball indenter. This minor load breaks through the sur- 
face to lessen the surface finish effects. Holding the preload for a specified dwell time, the baseline depth of indentation is measured. Thereafter, an additional load known as the major load, $\mathrm{F}_{1}$ is added to attain the total required test force. This load is maintained for a pre-determined duration known as the dwell time to permit elastic recovery. This major load is then released, returning to the preliminary load. After holding the preliminary test force for a specific dwell time, the final depth of indentation is measured. The difference in the baseline and final depth measurements give the Rockwell hardness value of the specimen, which was converted to a hardness number. The preliminary test force and the indenter were removed from the test samples (Equation 1).

$$
H R=E-e
$$

$F_{0}$ - Preliminary minor load

$F_{1}$ - Additional major load

$F$ - Total load

$e$ - permanent increase in depth of penetration due to the major load $F_{1}$ measured in units of $\mathrm{mm}$

$E$ - a constant depending on the form of indenter (100 units for diamond indenter and 130 units for steel ball indenter) $D$ - diameter of steel ball

$H R$ - Rockwell hardness.

\subsubsection{Wear resistance test}

A pin on disk machine following ASTM V03.02-2020 was employed to measure the wear rate of the sample. This involves sliding it over a cast iron surface at 40, 60, 80, 100, and $120 \mathrm{~kg}$ loads, sliding speed of $2.4 \mathrm{~m} / \mathrm{s}$ for 20 minutes at $50^{\circ} \mathrm{C}$ and $150^{\circ} \mathrm{C}$. Weight quantity of sample was measured using a digital weighing balance with $0.0001 \mathrm{~g}$ accuracy. The test procedures involve pressing the pin against the counterpart rotating against a cast iron disk with a counter surface roughness of $0.3 \mu \mathrm{m}$ by applying the load. A friction defecting arm linked to a strain gauge heto, loaded the specimens vertically into the rotating hardened cast iron disk. After a run through a fixed sliding length, the specimens were removed, cleaned, dried, and weighed again to calculate the loss in weight as a result of the wear resistance test. The difference in weight as measured before and after the evaluations affirm the wear of the sample as estimated using Equation (2) [21].

$$
\text { Wear rate }=\frac{\Delta W}{S}=\frac{W x-W y}{S}
$$

Where

$\Delta W$ - difference in weight of the sample before and after the test (mg)

$S$ - total sliding distance (m)

$W_{X}$ - initial weight of the sample (mg)

$W_{y}$ - final weight of the sample (mg).

\subsubsection{Water absorption test}

Specimen initial weight was measured and recorded as $W_{1}$ before soaking in distilled water for 24 hours. Thereafter, the specimens were removed, carefully cleaned to remove water droplets on the surface, weighed again, and recorded as $W_{2}$. The weight difference from the initial and final measurements was used to calculate the absorption rate using Equation 3, adopting the procedures followed by [21].

$$
\% \text { water absorption }=\frac{W 2-W 1}{W 1} \times 100 \%
$$

Where:

$W_{1}$ - sample initial weight

$W_{2}$ - sample final weight.

\subsubsection{Compression test}

This test defined the maximum compressive load a material can withstand before fracturing, known as the compressive strength. A Tensometer was used to establish the compressive strength of the composites. The compressive force which was loaded continuously until failure happened was applied to the samples. The force at which failure happened was recorded as the compressive strength of the material [27].

\subsubsection{Density test}

Archimedes' principle was adopted when measuring the density of the abrasive sandpaper composites produced. The buoyant force on a submerged object is equal to the weight of the fluid displaced. This effective mass underwater was its actual mass minus the mass of the fluid displaced. The difference between the actual and effective mass depicts the mass of water displaced and permits the calculation of the volume of an irregular shaped body. Therefore, the average density is the mass per unit volume of the sample (Equation 4).

$$
\text { Density }(\rho)=\frac{\text { Mass }}{\text { Volume }}=\frac{M}{V} \text {. }
$$




\section{Results and discussion}

The mechanical test results were analyzed to affirm the potential suitability of abrasive composites from PSK and CNS for frictional applications. The test data show the physicomechanical properties of the developed abrasive material considering the defined manufacturing procedures employed.

\subsection{Rockwell hardness test}

Rockwell hardness performance output as determined from the test evaluations on the PKS and CNS showed that composites hardness increases with increase binder concentration from 7.8 to $22.2 \mathrm{wt} \%$. A 9 HRB was obtained as the highest for $250 \mu \mathrm{m}$ sieve size while samples formed from $420 \mu \mathrm{m}$ sieve size show a reduced hardness value. Similarly, the CNS samples with $250 \mu \mathrm{m}$ sieve grade size exhibit the highest hardness of $8.40 \mathrm{HRB}$ compared with $420 \mu \mathrm{m}$ sieve grade size with a hardness of $7.92 \mathrm{HRB}$. This affirmed the influence of particle size on hardness characteristics of composites. Deductions from the performance investigation on the composites abrasive sandpaper revealed that

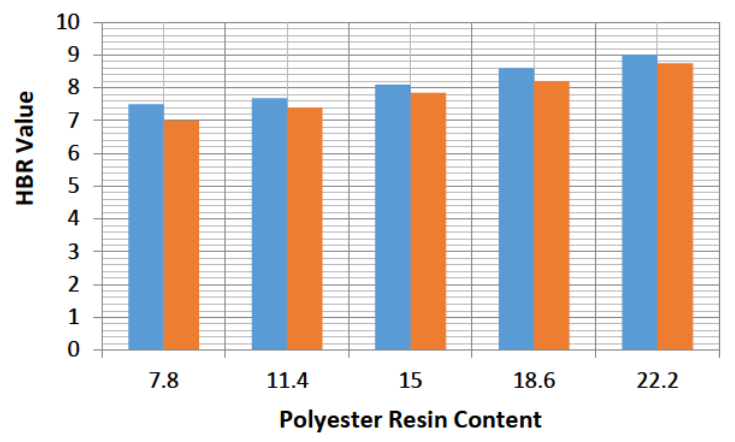

- PKS

Figure 5: Rockwell Hardness values of PKS \& CNS / Polyester composites for $250 \mu \mathrm{m}$ sieve size

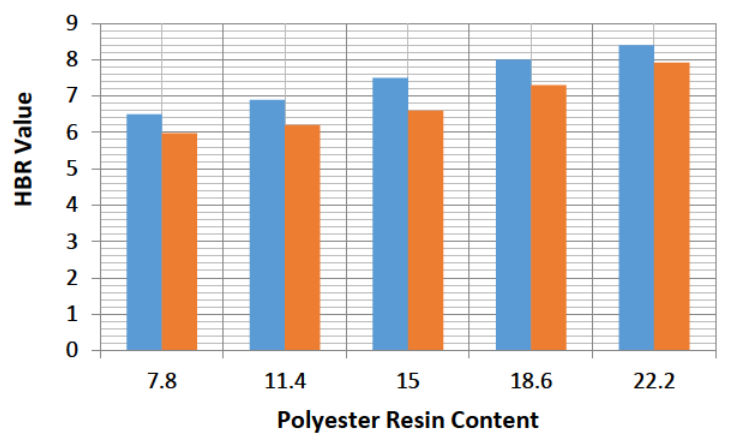

PKS CNS

Figure 6: Rockwell Hardness values of PKS \& CNS / Polyester composites for $420 \mu \mathrm{m}$ sieve size the hardness values of PKS and CNS increase proportionally as the percentage weight of binder increases as depicted in Figures 5 and 6 . This observed phenomenon may be linked to the compact interfacial bonding of the polyester resin binding the composites grain particles firmly together. Therefore, based on the sieve sizes used for the grits preparation, samples with $250 \mu \mathrm{m}$ size performed better with 9 HRB than 8.4 HRB for $420 \mu \mathrm{m}$ size for composites obtained from PSK. CNS abrasive composites exhibit the same trend with hardness values of $8.75 \mathrm{HRB}$ and $7.92 \mathrm{HRB}$ for both 250 $\mu \mathrm{m}$ and $420 \mu \mathrm{m}$ sieve sizes with $22.2 \mathrm{wt} \%$ polyester resin respectively. A similar inverse relationship between hardness and particle size was reported by [28] in the investigation of abrasive sandpaper hardness developed from composites using palm kernel and periwinkle shells.

\subsection{Wear resistance test}

The mean coefficients of friction for each of the sieve size of PKS and CNS compositions for the specimens produced are as presented in Figures 7-14 with the parameters used.

The wear process is characterized by fracture, tribochemical effects, and plastic flow. The transition between regions dominated by each of these effects often results in changes in wear rates with the applied load. The wear rate on the composites produced from PSK and CNS were per-

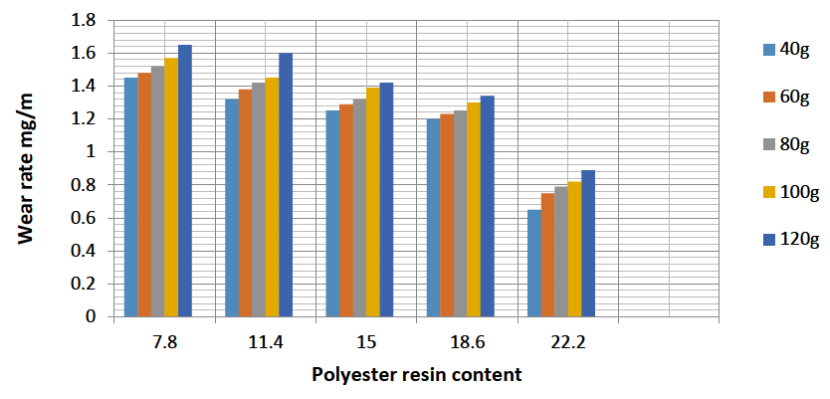

Figure 7: Wear rate of PKS / Polyester $250 \mu \mathrm{m}$ at $50^{\circ} \mathrm{C}$

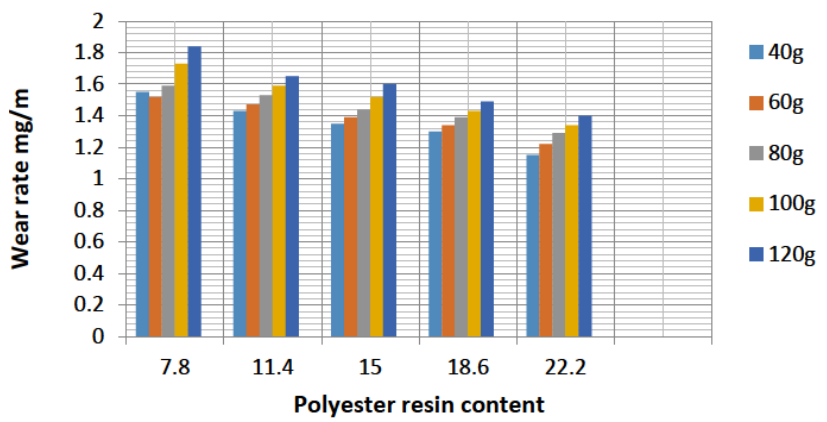

Figure 8: Wear rate of PKS / Polyester $250 \mu \mathrm{m}$ at $150^{\circ} \mathrm{C}$ 


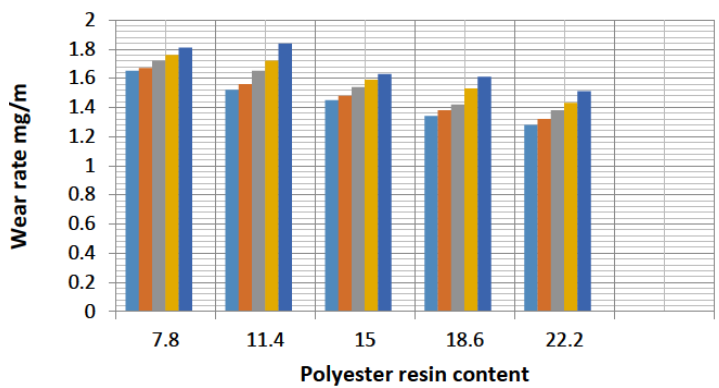

Figure 9: Wear rate of PKS / Polyester $420 \mu \mathrm{m}$ at $50^{\circ} \mathrm{C}$

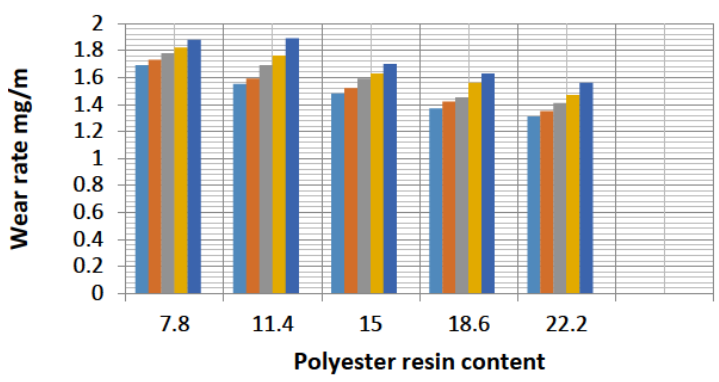

Figure 10: Wear rate of PKS / Polyester $420 \mu \mathrm{m}$ at $150^{\circ} \mathrm{C}$

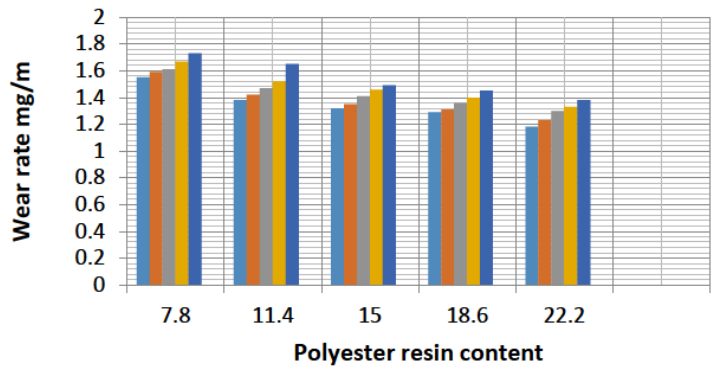

Figure 11: Wear rate of CNS / Polyester $250 \mu \mathrm{m}$ at $50^{\circ} \mathrm{C}$

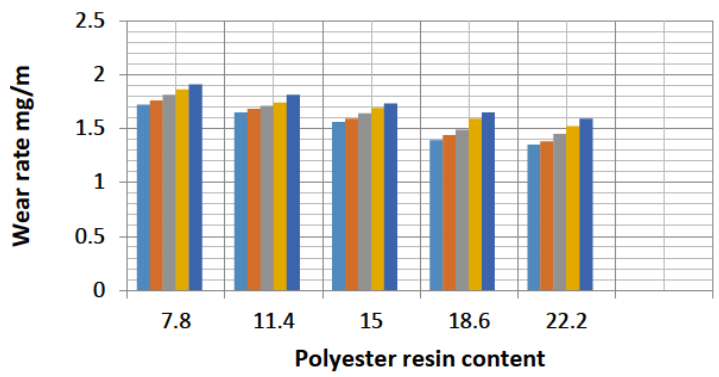

Figure 12: Wear rate of CNS / Polyester $250 \mu \mathrm{m}$ at $150^{\circ} \mathrm{C}$

formed at the two temperatures to understand their wear characteristics under heat resulting from the frictional application or action of the sandpaper. Based on the grit sizes of $250 \mu \mathrm{m}$ and $420 \mu \mathrm{m}$ at different concentrations of the palm kernel and coconut shells, specimens were evaluated. From the performance output, it was affirmed that wear rate increased with increasing palm kernel and coconut shell

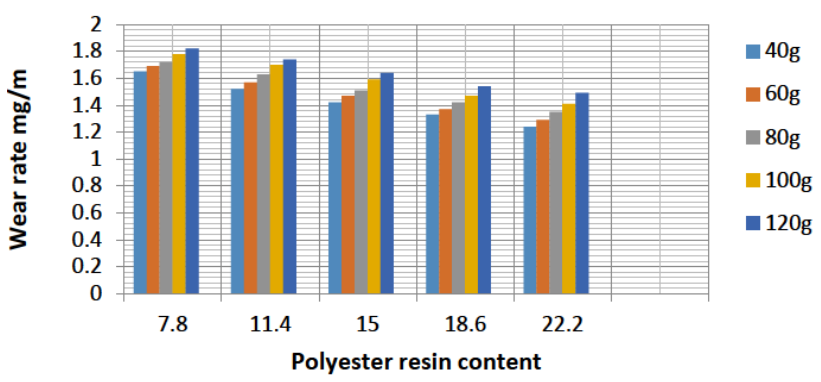

Figure 13: Wear rate of CNS / Polyester $420 \mu \mathrm{m}$ at $50^{\circ} \mathrm{C}$

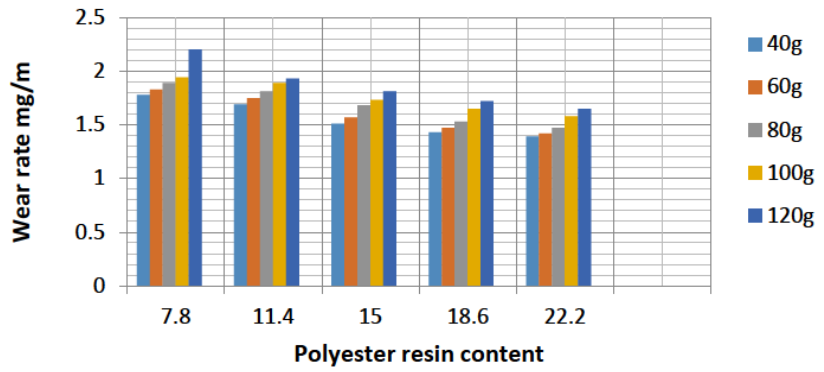

Figure 14: Wear rate of CNS / Polyester $420 \mu \mathrm{m}$ at $150^{\circ} \mathrm{C}$

grains percentage, the load applied, and temperature and reduces with a decrease in the particle sizes of the biomass grits. The previous study also documents similar trends as exhibited by the matrix composites to wear [28]. However, there was a decrease in the wear rate as the agro-wastes content of the sample reduces. The positive impact of the binder concentration at minimizing the wear rate of the sample was observed with $75.4 \mathrm{wt} \%$ of PKS and CNS at 22.2 wt $\%$ binder composition depicting the most wear-resistant characteristics. The increased interfacial bonding between the agro-materials and the binder induced this property. These relationships among hardness, wear resistance, and compressive strength with increased binder quantity was also emphasized in recent studies [17, 28].

\subsection{Water absorption test}

PKS and CNS as a natural fiber possess strong hydrophilic behaviour with many hydroxyl groups $(-\mathrm{OH})$ in the fibers. This peculiar nature of these materials enhances water uptake by these lignocellulosic materials due to the formation of hydrogen bonds between the fillers and water molecules. These hydroxyl $(-\mathrm{OH})$ groups make the materials exhibit low water resistance. Figures 15 and 16 show the water absorption test results of the developed abrasive sandpaper which tend to increase as the sieve sizes increase from 250 $\mu \mathrm{m}$ to $420 \mu \mathrm{m}$ in the formulation. This increase in water absorption rate may be as a result of the decrease in the 
interfacial bonding between the binder and filler element that produced an increase in porosity as confirmed by [20]. The highest water absorption value for the $250 \mu \mathrm{m}$ particle size of developed PKS based abrasive sandpaper was $7.53 \%$ as against the $250 \mu \mathrm{m}$ particle size of CNS based abrasive sandpaper with the highest absorption rate of $7.76 \%$. A 5.03\% water absorption value was affirmed in a study for wear properties of palm kernel reinforced composites for brake pad applications [12]. The difference may be as a result of the different constituent matrix formulations. PKS and the CNS composites have affinity to absorb water as a result of negative interaction with the grains and the resin binder.
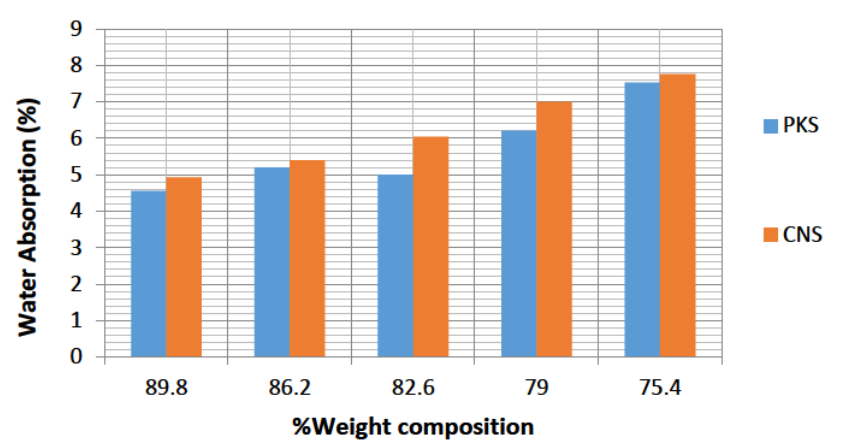

Figure 15: Water absorption characteristics of PKS \& CNS/\% weight composition for $250 \mu \mathrm{m}$ sieve size

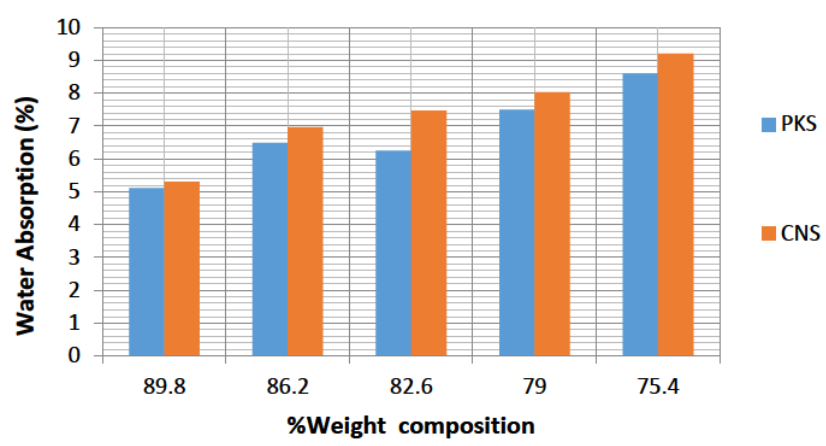

Figure 16: Water absorption characteristics of PKS \& CNS/\% weight composition for $420 \mu \mathrm{m}$ sieve size

\subsection{Compressive strength test}

Compressive strength behaviour exhibited based on the sieve sizes examined showed that the $250 \mu \mathrm{m}$ grit displayed the lowest compressive strength as compared to samples produced from $420 \mu \mathrm{m}$ sieve size. Composites with fine particles tend to induce brittleness which can reduce the compressive strength of the specimens. But increase in the amount of binder concentration from 7.8 to $22.2 \mathrm{wt} . \%$ in the composites help to increase the compressive strength of the material. The maximum compressive strengths gotten were $5.16 \mathrm{~N} / \mathrm{mm}^{2}$ and $4.98 \mathrm{~N} / \mathrm{mm}^{2}$ for $420 \mu \mathrm{m}$ particle size of palm kernel and coconut shells with $22.2 \mathrm{wt.} \%$ polyester resin respectively. However, the highest compressive strength values of $5.02 \mathrm{~N} / \mathrm{mm}^{2}$ and $4.93 \mathrm{~N} / \mathrm{mm}^{2}$ were recorded for $250 \mu \mathrm{m}$ particle size of palm kernel and coconut shells with $22.2 \mathrm{wt} \%$ polyester resin respectively (Figures 17 and 18).

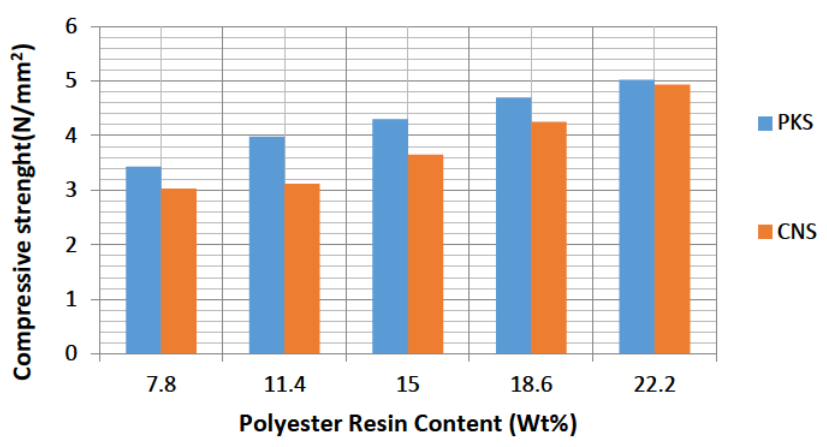

Figure 17: Compressive strength value of PKS \& CNS for $250 \mu \mathrm{m}$

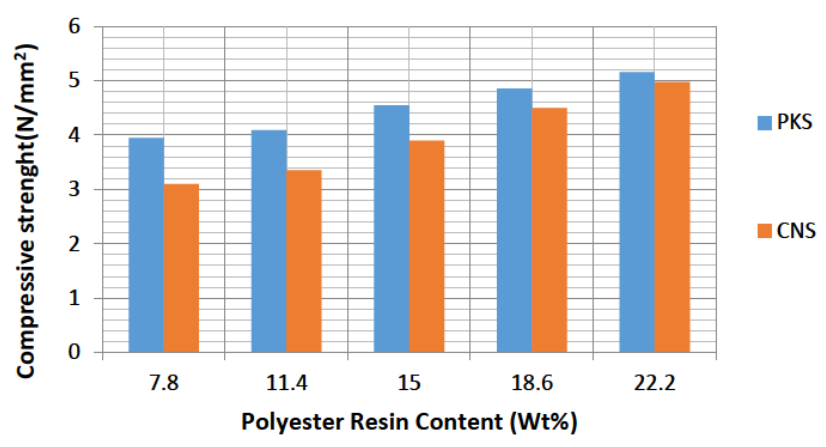

Figure 18: Compressive strength value of PKS \& CNS for $420 \mu \mathrm{m}$

\subsection{Density test}

Figures 19 and 20 show the variation of density with particle weight percentage variations. It was observed that an inverse relationship exists between density and percentage resin composition confirming an interaction between particle grains and the binder. Similarly, density also decreases with increasing particle weight compositions. Also, an inverse relationship was observed between density and 


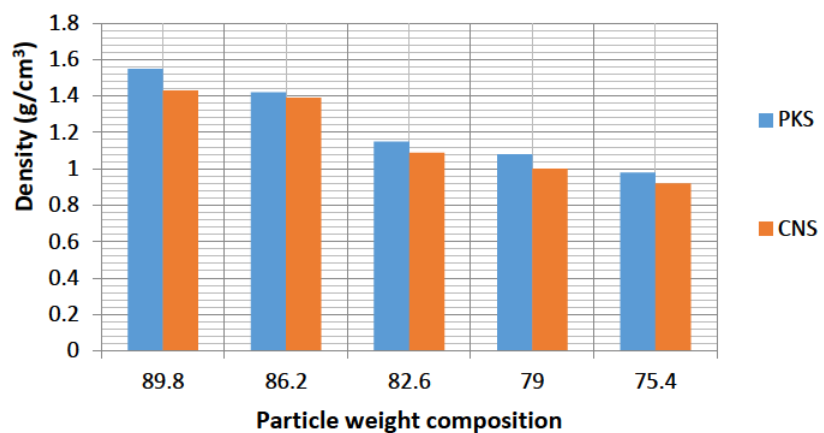

Figure 19: Density of PKS \& CNS/\% particle weight variation for $250 \mu \mathrm{m}$

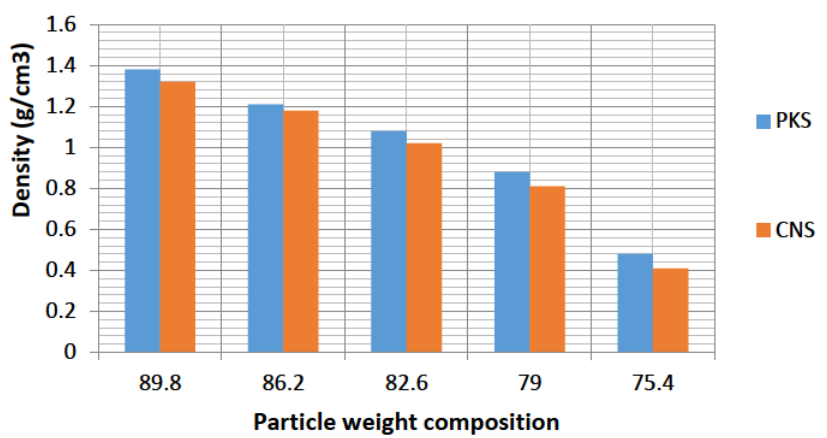

Figure 20: Density of PKS \& CNS/\% particle weight variation for $420 \mu \mathrm{m}$

the grit size of the materials. The specimen exhibited better density than those investigated by [12]. A $1.35 \mathrm{~g} / \mathrm{cm}^{3}$ density variation was observed between the developed and conventional abrasive sandpaper for the varied grit sizes.

\section{Conclusions}

The study investigated the suitability of composites abrasive sandpaper produced from agro-based materials for frictional applications. Two sieve sizes of $250 \mu \mathrm{m}$ and $420 \mu \mathrm{m}$ were used to produce the sample grits for the PKS and CNS that were mixed with polyester resin, cobalt naphthalene accelerator, and methyl ethyl ketone peroxide catalyst. The following conclusions can be drawn from the mechanical properties performance evaluations of the specimens:

1. Hardness increases as the percentage weight composition of the binder increases for the grit sizes studied.

2. Samples with a high percentage of binder exhibit better wear characteristics for the $250 \mu \mathrm{m}$ and 420 $\mu \mathrm{m}$ sieve sizes.
3. An increase in PKS and CNS percentage weight compositions along with the binder in the composites results in decrease water absorption properties.

4. Samples compressive strength increases as the percentage weight composition of binder increases over a range of 7.8 to $22.2 \%$ for both $250 \mu \mathrm{m}$ and $420 \mu \mathrm{m}$ sieve sizes studied.

5. As the percentage weight composition of PSK and CNS increases, the sample exhibit high density for both sieve sizes.

Acknowledgement: The assistance received from the technologists and laboratories where the tests were carried out is sincerely acknowledged. The authors also appreciate comments from the editor and anonymous reviewers that have enhanced the quality of this paper.

Funding information: The authors state no funding involved.

Author contributions: All authors have accepted responsibility for the entire content of this manuscript and approved its submission.

Conflict of interest: The authors state no conflict of interest.

\section{References}

[1] Alhassan EA, Olaoye JO, Adekanye TA, Okonkwo CE. Estimation of Wood Residues Generation from Sawmilling Activities and Energy Potential in Kwara State, Nigeria. Nat., Environ. Pollut. Technol., 2019 Sep 1;18(3):1023-7.

[2] Kibriya T, Tahir L. Sustainable Construction-Use of Blended Cements in High-Performance Concrete Pavements. Am. J. Civ. Eng. Archit., 2017;5(2):47-50.

[3] Traore YB, Messan A, Hannawi K, Gerard J, Prince W, Tsobnang F. Effect of oil palm shell treatment on the physical and mechanical properties of lightweight concrete. Constr. Build. Mater., 2018 Feb 10;161:452-60.

[4] Ogunwusi AA. The forest products industry in Nigeria. Afr. Res. Rev., 2012;6(4):191-205

[5] Aku SY, Yawas DS, Madakson PB, Amaren SG. Characterization of periwinkle shell as asbestos-free brake pad materials. The Pacif. J. of Sci. and Technol., 2012;13(2):57-63.

[6] Atoyebi OD, Awolusi TF, Davies IE. Artificial neural network evaluation of cement-bonded particle board produced from red iron wood (Lophira alata) sawdust and palm kernel shell residues. Case Stud Constr Mater. 2018 Dec 1;9:e00185.

[7] www.pwc.com/ng, X-raying the Nigerian Palm Oil Sector (Accessed $14^{\text {th }}$ Dec, 2020).

[8] Shafigh P, Mahmud HB, Jumaat MZ, Zargar M. Agricultural wastes as aggregate in concrete mixtures-A review. Constr. Build. 
Mater., 2014 Feb 28;53:110-7.

[9] Ikpambese KK, Gundu DT, Tuleun LT. Evaluation of palm kernel fibers (PKFs) for production of asbestos-free automotive brake pads. J. King Saud Univ. Eng. Sci., 2016 Jan 1;28(1):110-8.

[10] Alhassan EA, Olaoye J0. Briquetting characteristics of some agricultural residues using starch as a binder. Eth. J. of Envir. Stud. and Mgmt., 2015;8(6):692-707.

[11] Alsalami ZH, Harith IK, Dhahir MK. Utilization of dates palm kernel in high performance concrete. J. Build. Eng., 2018 Nov 1;20:166-72.

[12] Pujari S, Srikiran S. Experimental investigations on wear properties of Palm kernel reinforced composites for brake pad applications. Def. Technol., 2019 Jun 1;15(3):295-9.

[13] Oluwatuyi OE, Adeola BO, Alhassan EA, Nnochiri ES, Modupe $\mathrm{AE}$, Elemile 00, Obayanju T, Akerele G. Ameliorating effect of milled eggshell on cement stabilized lateritic soil for highway construction. Case Stud. Constr. Mater., 2018 Dec 1;9:e00191.

[14] Akinyemi BA, Okonkwo CE, Alhassan EA, Ajiboye M. Durability and strength properties of particle boards from polystyrene-wood wastes. J. Mater. Cycles Waste Manag., 2019 Nov;21(6):1541-9.

[15] Maksoud TM, Atia MR. Review of intelligent grinding and dressing operations. Mach. Sci. Technol., 2004 Dec 30;8(2):263-76.

[16] Kalácska G. An engineering approach to dry friction behaviour of numerous engineering plastics with respect to the mechanical properties. Express Polym. Lett., 2013 Feb 1;7(2).

[17] Aigbodion VS, Akadike U, Hassan SB, Asuke F, Agunsoye JO. Development of asbestos-free brake pad using bagasse. Tribol. Ind. 2010;32(1):12-7.

[18] Obot MU, Yawas DS, Aku SY. Development of an abrasive material using periwinkle shells. J. King Saud Univ. Eng. Sci., 2017 Jul 1;29(3):284-8.
[19] Wai JJ, Lilly MT. Manufacturing of Emery Cloth (Sand Paper) from Local Raw Materials. Glob. J. of Eng. Res., 2002;1(1):31-8.

[20] Odior AO, Oyawale FA. Formulation of silicon carbide abrasives from locally sourced raw materials in Nigeria. In Proceedings of the world congress on engineering 2011 (Vol. 1, pp. 6-8).

[21] Edokpia RO, Aigbodion VS, Obiorah OB, Atuanya CU. Evaluation of the Properties of Ecofriendly Brake Pad Using Egg Shell Particles', Gum Arabic. Science Direct.

[22] Bashar DA, Madakson PB, Manji J. Material selection and production of a cold-worked composite brake pad. World J. Eng. Pure Appl. Sci., 2012 May 1;2(3):92.

[23] Dagwa IM, Ibhadode AO. Design and manufacture of automobile disk brake pad test rig. Nigerian J Eng Res Develop. 2005;4(3):1524.

[24] Akinyemi BA, Ojediran J, Olawale O, Ayanwola S. Efficacy of expanded polystyrene as fine aggregate in cement mortars modified with latex paint as an alternative to polymer admixture. J. Mech. Behav. Mater., 2020 Dec 9;29(1):163-8.

[25] FEPA Abrasives, 2013. P-grit sizes coated abrasive products. Retrieved March 15, 2014 from <http://www.fepaabrasives.org/Abrasiveproducts/Grains/Pgritsizescoated.aspx>

[26] Jain N, Somvanshi KS, Gope PC, Singh VK. Mechanical characterization and machining performance evaluation of rice husk/epoxy an agricultural waste based composite material. J Mech Behav Mater. 2019;28(1):29-38.

[27] Nagajothi S, Elavenil S. Parametric studies on the workability and compressive strength properties of geopolymer concrete. J Mech Behav Mater. 2018;27(3-4).

[28] Yawas DS, Aku SY, Amaren SG. Morphology and properties of periwinkle shell asbestos-free brake pad. J King Saud Univ Eng Sci. 2016;28(1):103-9. 